\title{
Effect of Inlet Airflow Direction on the Indoor Environment of a Naturally Ventilated Room using CFD
}

\author{
Ghogare Abhijeet Ganesh, Shobha Lata Sinha, Tikendra Nath Verma
}

\begin{abstract}
The present study emphases the numerical investigation of the change in the overall indoor environment of a mechanically heated room, due to alteration in direction of the cold air stream at the inlet. This study is important to find the correlation between the configuration of altered geometry on the indoor environment quality and human comfort. Different case studies have been studied by altering the direction of the flow of the unidirectional velocity vector $(U)$ by turning clockwise around the Z-axis and keeping other geometry parameters unaltered. Numerically simulated observations have been analyzed to study the effect of changed airflow direction at the inlet on indoor environmental quality Slight variations in the indoor environment were observed due to changed inlet angle set from $0^{\circ}-60^{\circ}$, but for the largest angle setting of $\left(80^{\circ}\right)$, considerable changes were observed ins temperature and flow patterns. When the inlet vent angle increased from $0^{\circ}-80^{\circ}$, the airflow and thermal pattern in room changes. More swirls and circulation observed in the case of higher inlet angles. PPD values for subsequent cases were found under control for all the set of inlet angles. The lowest PPD and PMV values observed for an $80^{\circ}$ inlet angle setting. The outcomes of the research would be valuable for the design and optimization of local buildings and more energy can be hoarded by proper installations of equipment and inlet vent location.
\end{abstract}

Keywords: Computational fluid dynamics; Comfort temperature; velocity vector; inlet angle; radiator; PPD;

\section{INTRODUCTION}

Nowadays energy is an essential resource and demand for energy is also growing. Many negative effects of energy production can be seen in the environment, such as environmental pollution and global warming. In order to tackle the global warming effect and the growing cost of production, energy needs to be conserved. A huge expanse of energy can be hoarded in the building sector alone. Building sector alone demands around $40 \%$ of the entire energy expenditure over the globe and $30 \%$ the $\mathrm{CO}_{2}$ emission. From 1971 to 2014 energy consumption on the global level increased by $90 \%$ and the building sector contributed more fraction of this increased energy consumption [1-2]. The study of HVAC can analyze and improve energy demand in the building sector.

Revised Manuscript Received on February 05, 2020.

* Correspondence Author

Ghogare Abhijeet Ganesh, Research Scholar (Ph.D.), Department of Mechanical Engineering.NIT Raipur.

Shobha Lata Sinha, Professor, Department of mechanical engineering, NIT Raipur.

Tikendra Nath Verma, Assistant Professor in the department of mechanical engineering at NIT Manipur

(c) The Authors. Published by Blue Eyes Intelligence Engineering and Sciences Publication (BEIESP). This is an open access article under the CC BY-NC-ND license (http://creativecommons.org/licenses/by-nc-nd/4.0/)
The principal objective of HVAC analysis is to maintain the appropriate balance between energy consumption and comfort conditions in the building. A good level of thermal comfort in an indoor environment amplifies productivity and reduces the risk of human health $[3,4]$. There have been a number of studies were conducted on the indoor environmental quality, such as "Thermal comfort and energy-saving enhancements in an office room" [5], "Residential building energy consumption characteristics and energy demand" [6], "the study of thermal comfort in a room by various heating methods" [7], "energy consumption in office room for displacement ventilation". [8], "a review of comfort, health, and energy to understand daily energy use and wellbeing for the development of a new approach to study comfort" [9], and many others [10-18].According to IEA indoor environmental conditions in a building depends on few major factors, (1) Outdoor climate conditions, (2) building envelopes, (3) building design factors, (5) building set-up and maintenance, (4) building energy consumption and amenities arrangement, (6) activities of occupiers [4].

The climate condition on the globe varies according to its geographical location. People in a higher temperature region feel comfortable in a warmer indoor environment as compare to the cold climate people. Humidity is also an important factor that affects the overall occupant comfort [19]. In several parts of the earth, weather conditions are very harsh and indoor environment needs to be artificially/mechanically maintained to a human comfort level. Climate conditions in that region also influence the type of clothing used by people. Cloths on the human body act as an insulator and limit the heat exchange between the occupant and the surrounding environment [20, 21]. The amount of insulation given by clothes is expressed in terms of clo. The value of unit 1 clo is given as $0.155 \mathrm{~m}^{2 \circ} \mathrm{C} / \mathrm{W}$. Clothing factors affect the occupier's sensitivity to thermal comfort and eventually affect the energy essential to regulate the thermal comfort in the room. The satisfactory clothing insulation factor for a human body in summer is 0.59 clo and for winter is 0.69 clo $[22,23]$. If the room is occupied, the presence of humans raises the mean temperature of the indoor environment by a considerable amount [24]. The metabolic rate of human acts as a source of uneven heat flux. The internal heat generated by the human occupant depends on the activity level of the human body and environmental conditions, a high level of activity results in high heat flux. [25]. The SI unit for the metabolic rate is met and $1 \mathrm{met}=58.2 \mathrm{~W} / \mathrm{m}^{2}$. 
The amount of cooling or heating required in the room depends on the number of occupiers and their activity level; it may vary with time [26]. To maintain the satisfactory indoor environmental quality, the indoor air properties in the occupied zone needs to be controlled. The nature of the ventilation method used in building design i.e. natural or

artificial also affects the thermal comfort required by the occupant. In artificially ventilated buildings occupant feel comfortable for a temperature range of $20-25^{\circ} \mathrm{C}$. In the case of naturally ventilated buildings occupants can tolerate a higher range of temperatures up to $25-28^{\circ} \mathrm{C}$ [5]. Air movement in the occupied zone also affects the thermal comfort of the human occupant. The arrangement of high air movement at low temperature may cause a problem related to draught, hence at low-temperature low velocity and for high-temperature high velocity is preferred for better indoor thermal conditions. The temperature of flowing air changes the human perception of air movement [28, 29].

HVAC (heating, ventilation and air conditioning) deals with the study of airflow movement and temperature analysis of the indoor environment. Problems related to HVAC can be analyzed and solved using Computational Fluid Dynamics (CFD) solver [30]. CFD is a valuable tool for simulating the pattern of air movement, velocity, temperature and many more. There are many research article presented earlier related to indoor environment prediction using CFD [33].

In the present study, a 3-D modeled naturally ventilated room was used. The same geometrical model was used in earlier experimental [7] and numerical [33, 34] studies. In ANSYS FLUENT software, the inlet airflow direction is always taken normal to the YZ plane and along $\mathrm{X}$-axis. This study focuses more on the direction of the inlet cold air stream instead of magnitude and spotlights the effect of a change in direction of cold air inlet stream on the room airflow and indoor thermal conditions. The unidirectional vector of inlet velocity was rotated along the Z-axis in a clockwise direction through an angle $\theta$. The inlet angle $(\theta)$ was changed by the difference of $10^{\circ}$ for each case study (Fig.1), not each case was illustrated in results, but rather all related data discussed in the result and discussion. The outcomes of the current investigation were well validated with the experimental (Fig.3) and numerical results (Fig.4). This study is centered on the analysis of heat and flow situations for various inlet air stream directions. The thermal conditions in the occupied zone depend on the air temperature at the inlet and probably on the direction of the fresh cold air stream. The CFD simulations were carried out for five different case studies with different inlet air stream direction.

\section{PHYSICAL PROBLEM}

\section{A. The CFD Room Model}

The numerical model of the 3 -D room having measurements of $4.8 \mathrm{~m} \times 2.6 \mathrm{~m} \times 2.4 \mathrm{~m}(\mathrm{~L} \times \mathrm{H} \times \mathrm{W})$ was designed by means of ICEM CFD software. The similar geometry of the room was earlier used in experimental work by Oleson et. al. [7] and numerical work by Myhren et.al [33], Horikiri et.al. [24]. For the detailed room, a geometry research article [7] can be referred to. The CFD modeled room can be referred to from the available research article [37]. The CFD modeled room has no furniture and occupants. The empty room has been modeled for studying indoor environmental conditions. An empty room (Fig.1) consists of the localized heat source double-panel radiator, glazed glass window, adiabatically insulated walls, ceiling and floor, one adjustable inlet vent, and outlet vent. The detailed specification of geometry is listed below in table 1 .

\section{B. Monitoring planes and lines}

The comfort zone in the room is defined by the region $0.6 \mathrm{~m}$ away from each wall and up to the height of $1.8 \mathrm{~m}$, which is normally the zone preferred by a human for occupancy. To study the comfortable environment in the occupied zone, four monitoring lines (11, 12, 13, and 14) at a distance of $\mathrm{X}=0.6 \mathrm{~m}, \mathrm{X}=1.8 \mathrm{~m}, \mathrm{X}=3.0 \mathrm{~m}, \mathrm{X}=4.2 \mathrm{~m}$ have been plotted in the room fluid domain. The mid-plane passing over the origin and normal to the $\mathrm{YZ}$ plane $(\mathrm{Z}=0)$ was also plotted to analyze the general room comfort condition (Fig.1).

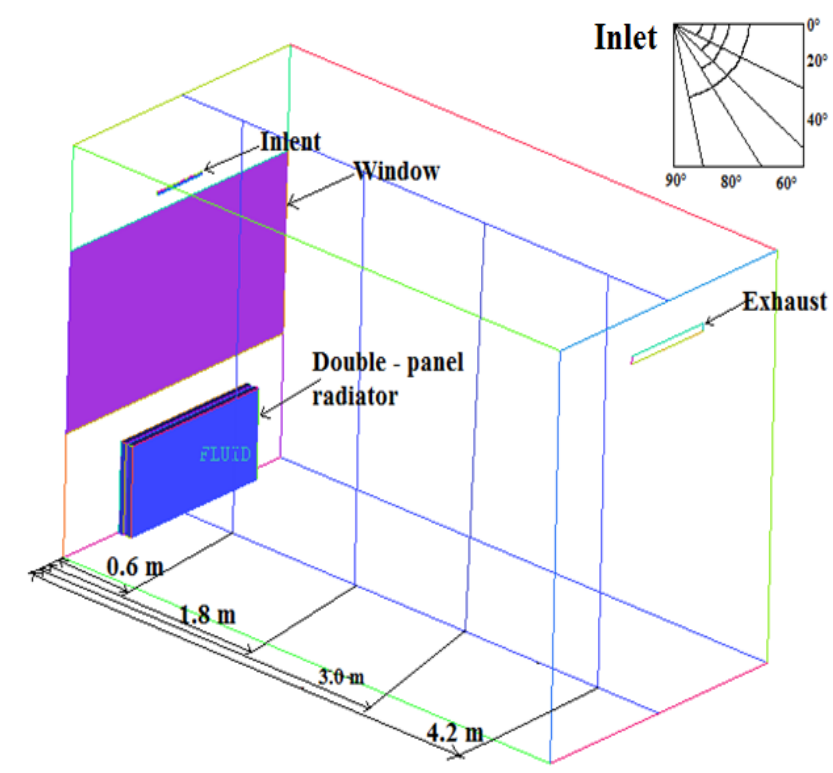

Fig.1. Graphical interpretation of 3-D modeled room.

Table-I: Design of geometry

\begin{tabular}{|c|c|c|}
\hline Geometry (objects) & $\begin{array}{l}\text { Dimensions } \\
(\mathrm{L} \times \mathrm{B} \times \mathrm{H})\end{array}$ & $\begin{array}{l}\text { Location in } \\
\text { room }\end{array}$ \\
\hline Inlet & $0.50 \times 0.02 \mathrm{~m}^{2}$ & $\begin{array}{l}\text { Above } \\
\text { window. }\end{array}$ \\
\hline Outlet & $0.80 \times 0.05 \mathrm{~m}^{2}$ & $\begin{array}{l}\text { A wall } \\
\text { reverses to } \\
\text { the window. }\end{array}$ \\
\hline Radiator & & Along the \\
\hline 1) Plate 1 & $1.40 \times 0.05 \times 0.60 \mathrm{~m}^{3}$ & center of the \\
\hline 2) Plate 2 & $1.40 \times 0.05 \times 0.60 \mathrm{~m}^{3}$ & $\begin{array}{l}\text { wall and } \\
\text { under the } \\
\text { window, } \\
0.01 \mathrm{~m} \text { Left } \\
\text { from the } \\
\text { wall. }\end{array}$ \\
\hline
\end{tabular}




\section{Boundary conditions}

The above model was designed to maintain the required indoor comfort conditions in cold climate conditions. The ambient environment of Sweden in the wintertime is actual icy, the fresh air current at the inlet of $-5^{\circ} \mathrm{C}$ was entering the room from an adjustable inlet vent. The air temperature in the room before launching the CFD analysis was taken as 16 ${ }^{\circ} \mathrm{C}$. All the walls were perfectly bounded and insulated to avoid the heat interaction between room indoor and outdoor environment. For decent indoor environmental conditions, the indoor air temperature should be maintained between $20-22^{\circ} \mathrm{C}$ [26]. To maintain the required thermal comfort conditions in the occupied zone the unvarying heat flux was specified to the double-panel radiator. For the healthy indoor environment, the inlet air volume flow rate was kept constant at $7.3 \mathrm{l} / \mathrm{s}$ which gives an air change rate of $0.8 \mathrm{~h}-1$ [40]. Due to the low volume flow rate of inlet air $(\operatorname{Pr}=0.7)$, the flow has been considered incompressible throughout the study. Since it is found that Gr / Re2 >> 1 and, therefore, natural convection is the dominant factor supportive of heat transfer. Hence, attention should be given to the following air properties, such as the thermal expansion coefficient $(\alpha)$, thermal conductivity $(\mathrm{k})$, density $(\rho)$, specific heat $(\mathrm{Cp})$ related to natural convection. Table 2 shows the boundary conditions incorporated in the present study.

Table-II: Boundary conditions

\begin{tabular}{|l|l|}
\hline Geometry & \\
\hline Inlet & \\
1) Constant temperature & \\
2) Uniform air flow rate & \\
\hline Exhaust & \\
\hline Window & \\
$\mathrm{T}_{\mathrm{W}}=$ Constant, & \\
\hline Walls ( Bare to the open-air ambiances) & \\
\hline Radiator (Double-panel) & \\
\hline Viscous model & \\
\hline Radiation model & \\
\hline Scheme for pressure & \\
\hline
\end{tabular}

\section{NUMERICAL METHODOLOGY}

\section{A. Case description}

The three-dimensional ventilated room dimensions are $4.8 \mathrm{~m} \times 2.6 \mathrm{~m} \times 2.4 \mathrm{~m}$ in length, height, and width respectively. The room has entirely insulated walls including floor and ceiling, double-panel radiator as a localized heat source, one adjustable inlet, and a solitary outlet vent. The modeled room was entirely empty except the presence of the radiator below the glazed glass window. The present study is based on cold climate atmospheric conditions. The ambient conditions in the wintertime of Sweden are very cold $\left(-5^{\circ} \mathrm{C}\right)$ and hence the radiator was employed as a heat source to maintain the human satisfactory warm indoor environment [33].

Table-III: Case study

\begin{tabular}{lc}
\hline Case no. & $\begin{array}{l}\text { Inlet vent angle for cold air } \\
\text { inlet (Degrees) }\end{array}$ \\
\hline Case 1 & $0^{\circ}$ \\
Case 2 & $20^{\circ}$ \\
Case 3 & $40^{\circ}$ \\
Case 4 & $60^{\circ}$ \\
Case 5 & $80^{\circ}$ \\
\hline
\end{tabular}

This study focuses on the effect of direction of the inlet air stream on flow and thermal properties of the indoor environment with the help of adjustable inlet vent. By analyzing various case studies performed (Table 3), found that the considerable changes in the indoor environment were recorded due to the changed direction of the inlet cold
Boundary conditions

$\mathrm{T}_{\text {air }}=-5^{\circ} \mathrm{C}$

$\mathrm{v}$ air $=7.3 \mathrm{l} / \mathrm{s}$

Outflow

$\mathrm{T}_{\mathrm{w}}=14^{\circ} \mathrm{C}$

Adiabatic $(\mathrm{q}=0)$

Constant heat flux,

Radiator surface temperature kept constant at $40-42^{\circ} \mathrm{C}$.

Standard k- $\varepsilon$ turbulence model.

Discrete ordinate (DO)

The second-order, a SIMPLE algorithm.

air stream. The inlet vent angle was changed for each case study as shown in fig.1.

\section{B. Airflow and heat transfer}

In the current study, ANSYS FLUENT 18.1 has been used to numerically investigate the indoor environmental conditions of the 3D ventilated room. The ReynoldsAverage Navier-Stokes (RANS) was implemented along with the two-equation standard $\mathrm{k}-\varepsilon$ turbulent model. $\mathrm{Y}$ plus was controlled by generating fine mesh at walls and enhanced wall treatment model used to capture the fluid domain near the walls. To study the indoor airflow and the turbulence generated, the sensitive and low-cost viscous model, the standard $k-\varepsilon$ model has been used by calculating turbulent kinetic energy and its dissipation rate symmetrically[35, 36]. CFD is used to resolve the Continuity, momentum, and energy equations of the airflow. The main focus of this study is on radiation and heat transfer by convection due to the temperature difference in the fluid domain. As the thermal conductivity of the air is negligible and the walls are completely insulated, the heat transfer due to the conduction is totally neglected. To capture the effect of heat source radiations on flow and temperature distribution, discrete ordinates radiation scheme was employed [37, 38]. The air density Boussinesque approximation was applied to study the complete buoyancy influence and to analyze the smallest effect on the room indoor environment. The body weighted scheme works well in interpolating pressure and further properties in a strong buoyancy flow [39]. 
To solve the non-linearity of the momentum equation, the velocity pressure coupled with the semi-implicit method for the pressure-linked equation (simple) algorithm was employed. [6, 39].

\section{Mesh independence test and description of the model}

After building a room geometry using ICEM CFD, the

unstructured hex mesh has been generated for good computational accuracy. To further improve the accuracy of the results, three different grid size resolutions (179000, 289000 and 386000) have been analyzed and compared. The outcomes for all three grid sizes plotted in terms of comfort temperature of an indoor environment at four different locations and compared with the previously performed numerical study [33, 34] for the same model.

Fig. 2 shows almost the same comfort temperature trends for all three grid sizes with a minor temperature variation of $0.5^{\circ} \mathrm{C}$. The closest match to the numerical result was observed in 289000-grid resolution and hence used for further calculations [30, 34]. To forecast optimal cost and to attain essential result accuracy, grid independence test plays an important role.

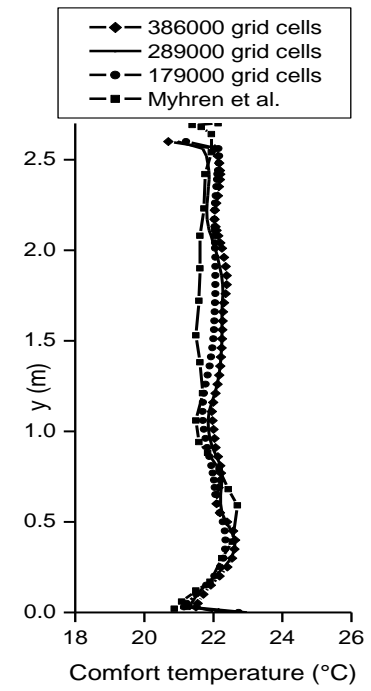

(a) $X=0.6 \mathrm{~m}$

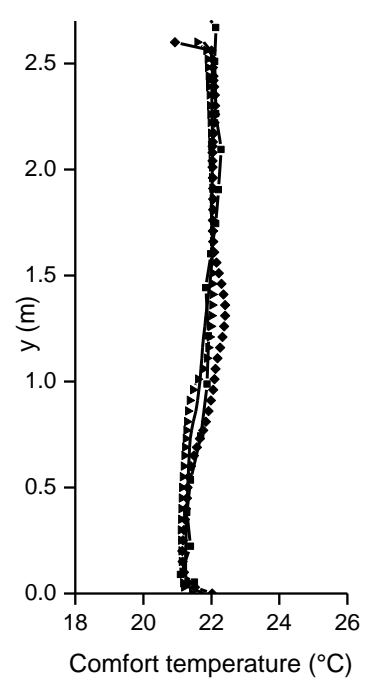

(c) $\mathrm{X}=3.0 \mathrm{~m}$

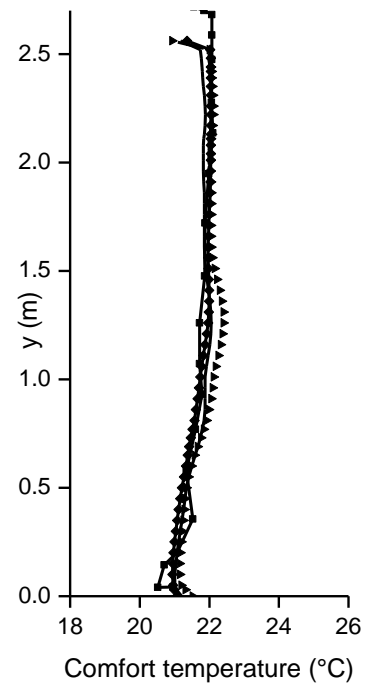

(b) $\mathrm{X}=1.8 \mathrm{~m}$

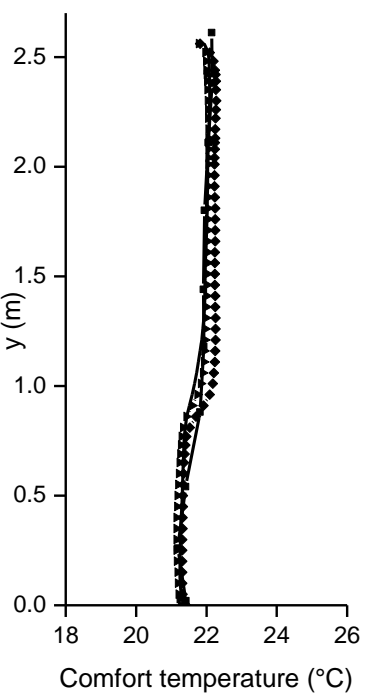

(d) $\mathrm{X}=4.2 \mathrm{~m}$
Fig.2 Mesh independence test for a CFD model at four locations (a) $l_{1}$, (b) $I_{2}$, (c) $l_{3}$, (d) $l_{4}$

\section{Numerical model and thermal comfort}

The numerical study of the present research objective entails resolving the governing equations of mass, momentum and energy. Ansys solves the conservation equations for the mass, momentum, and energy for all flows. Energy conservation equations need to be solved for problems related to thermal interactions. Ansys Fluent gives the provision to use various types of turbulent models, the appropriate turbulent model should be selected as per the requirement. The governing equations of fluid dynamics and energy equations solved by software are listed below, in equations (1-5) [41].

$$
\begin{gathered}
\frac{\partial \rho}{\partial t}+\nabla \cdot\left(\rho_{V}\right)=0 \\
\frac{\partial(\rho u)}{\partial t}+\nabla \cdot\left(\rho u_{V}\right) \\
=-\frac{\partial p}{\partial x}+\frac{\partial \tau_{x x}}{\partial x}+\frac{\partial \tau_{y z}}{\partial y}+\frac{\partial \tau_{z x}}{\partial z} \\
+\rho f_{x}
\end{gathered}
$$

The energy equation resolved by Ansys fluent is shown below,

$$
\begin{aligned}
\frac{\partial}{\partial t}(\rho E)+\nabla \cdot(\vec{V} & (\rho E+p)) \\
& =\nabla \cdot\left(k_{e f f} \nabla T\right. \\
& -\sum_{j} h_{j} \vec{J}_{j}+\left(\begin{array}{c}
\left.\left.\underset{\tau_{e f} \cdot \cdot \vec{V}}{=}\right)\right)
\end{array}\right.
\end{aligned}
$$

The $\mathrm{k}-\varepsilon$ turbulence model has been used to solve the Reynolds average Navier - Stokes equation. The respective equations for turbulent kinetic energy (k), and the dissipation rate of turbulent kinetic energy $(\varepsilon)$ are mentioned in the equation given below $(6,7)$. Table 4 . Shows all the model constants used in the standard k- $\varepsilon$ turbulent model. In addition to convective heat transfer, radiation heat transfer has also been carefully studied to consider the radiation effect of the radiator on the indoor environment. The thermal band for radiation heat transfer was considered between $0.1 \mu \mathrm{m}$ to $1000 \mu \mathrm{m}$ [42]. To analyze the effect of radiation from radiator surface the thermal band between $0.1 \mu \mathrm{m}$ to $1000 \mu \mathrm{m}$ has been considered [42]. Along with the convective heat transfer, the radiation temperature also has an impact on the indoor environment. 
Equation (8) mentions the transport equation of the desecrating ordinate $(\mathrm{DO})$ radiation model. The predefined radiation model in Ansys fluent takes into account the origin of radiation [20].

$$
\begin{aligned}
\frac{\partial}{\partial \mathrm{t}}(\rho \mathrm{k})+\frac{\partial}{\partial \mathrm{x}_{\mathrm{i}}}\left(\rho \mathrm{ku}_{\mathrm{i}}\right) & \\
= & \frac{\partial}{\partial \mathrm{x}_{\mathrm{j}}}\left[\left(\mu+\frac{\mu_{\mathrm{t}}}{\sigma_{\mathrm{k}}}\right) \cdot \frac{\partial \mathrm{k}}{\partial \mathrm{x}_{\mathrm{j}}}\right]+\mathrm{G}_{\mathrm{k}}+\mathrm{G}_{\mathrm{b}}-\rho \varepsilon \\
& -\mathrm{Y}_{\mathrm{m}}+\mathrm{S}_{\mathrm{k}}
\end{aligned}
$$

$$
\begin{aligned}
\frac{\partial}{\partial \mathrm{t}}(\rho \varepsilon)+\frac{\partial}{\partial \mathrm{x}_{\mathrm{i}}}\left(\rho \varepsilon \mathrm{u}_{\mathrm{i}}\right) & \\
& =\frac{\partial}{\partial \mathrm{x}_{\mathrm{j}}}\left[\left(\mu+\frac{\mu_{\mathrm{t}}}{\sigma \varepsilon}\right) \cdot \frac{\partial \varepsilon}{\partial \mathrm{x}_{\mathrm{j}}}\right] \\
& +\mathrm{C}_{1 \varepsilon} \cdot \frac{\varepsilon}{\mathrm{k}}\left(\mathrm{G}_{\mathrm{k}}+\mathrm{C}_{3 \varepsilon}+\mathrm{G}_{\mathrm{b}}\right)-\mathrm{C}_{2 \varepsilon} \cdot \rho \cdot \frac{\varepsilon^{2}}{\mathrm{k}} \\
& +\mathrm{S}_{\varepsilon}
\end{aligned}
$$

$$
\begin{aligned}
& \nabla(I(\vec{r}, \vec{s}) \vec{s})+\left(a+\sigma_{s}\right) I(\vec{r}, \vec{s}) \\
& =a n^{2} \frac{\sigma T^{4}}{\pi}+\frac{\sigma_{s}}{4 \pi} \int_{0}^{4 \pi} I(\vec{r}, \vec{s}) \\
& \times \phi\left(\vec{r}, \vec{s}_{s}^{\prime}\right) d \Omega^{\prime}
\end{aligned}
$$

Table-IV: Model constant for standard k- $\varepsilon$

\begin{tabular}{ll}
\hline $\mathrm{C}_{1 \varepsilon}$ & 1.44 \\
$\mathrm{C}_{2 \varepsilon}$ & 1.92 \\
$\mathrm{C}_{\mu}$ & 0.09 \\
$\sigma_{k}$ & 1.0 \\
$\sigma_{\varepsilon}$ & 1.3 \\
\hline
\end{tabular}

The flow rate of fresh inlet air was very low and hence considered as an incompressible flow. The flow was considered to be dominated by natural convection and hence by buoyant force. The dimensionless quantities used for the above study are listed below (9-12),

$$
\begin{aligned}
& \mathrm{Gr}=\frac{g \beta\left(\mathrm{T}_{\text {radiator }}-\mathrm{T}\right) \mathrm{L}^{3}}{\mathrm{v}^{2}} \\
& \mathrm{Ra}=\frac{\mathrm{g} \beta\left(\mathrm{T}_{\text {radiator }}-\mathrm{T}\right) \mathrm{L}^{3}}{\mathrm{v} \alpha} \\
& \mathrm{Re}=\frac{\rho \mathrm{VL}}{\mu} \\
& \rho=\rho_{\text {ref }}\left(1-\beta\left(\mathrm{T}-\mathrm{T}_{\text {ref }}\right)\right)
\end{aligned}
$$

There are a few important parameters that need to be controlled for obtaining high-quality thermal comfort in an indoor environment. The level of overall comfort of the human body can be identified using the predicted mean vote (PMV) and predicted percentage discomfort (PPD) index. The PMV index shows the mean average value of the large collection of voters on the comfort scale. While the PPD shows the percentage of people from large group dissatisfied with the neighboring thermal environment. For decent thermal conditions, the suggested PMV value is in range of $-0.5<$ PMV $<+0.5$ and PPD $<10 \%$. The PMV and PPD index have been calculated using the following equations $(10,14,15)[24]$.

$$
\begin{aligned}
& \mathrm{PMV}=\left(0.03 \mathrm{e}^{-0.036 \mathrm{M}}+0.028\right)\left\{(\mathrm{M}-\mathrm{W})-3.05 \times 10^{-3}\right. \\
& \\
& \times\left[5733-6.99(\mathrm{M}-\mathrm{W})-\mathrm{P}_{\mathrm{a}}\right]-0.42 \\
& \times[(\mathrm{M}-\mathrm{W})-58.15]-1.7 \\
& \times 10^{-5} \mathrm{M}\left(5867-\mathrm{P}^{\mathrm{a}}\right) \\
&-0.0014 \mathrm{M}\left(34-\mathrm{t}_{\mathrm{a}}\right)-3.96 \times 10^{-3} \mathrm{f}_{\mathrm{cl}} \\
& \times\left[\left(\mathrm{t}_{\mathrm{cl}}+273\right)^{4}-\left(\mathrm{t}_{\mathrm{r}}+273\right)^{4}\right] \\
&\left.-\mathrm{f}_{\mathrm{cl}} \mathrm{h}_{\mathrm{c}}\left(\mathrm{t}_{\mathrm{cl}}-\mathrm{t}_{\mathrm{a}}\right)\right\}
\end{aligned}
$$

While

$$
\begin{aligned}
\mathrm{t}_{\mathrm{cl}}=35.7-0.028 & (\mathrm{M}-\mathrm{W}) \\
& -\mathrm{C}_{\mathrm{cl}}\left\{3.96 \times 10^{8} \mathrm{f}_{\mathrm{cl}}\right. \\
& \times\left[\left(\mathrm{t}_{\mathrm{cl}}+273\right)^{4}-\left(\overline{\mathrm{t}}_{\mathrm{r}}+273\right)^{4}\right] \\
& \left.-\mathrm{f}_{\mathrm{cl}} \mathrm{h}_{\mathrm{c}}\left(\mathrm{t}_{\mathrm{cl}}-\mathrm{t}_{\mathrm{a}}\right)\right\}
\end{aligned}
$$

The thermal comfort indices can also be calculated using FORTRAN code using Fluent CFD [24]. Due to the absence of human model few assumptions were done in the present study. For the normal winter indoor environment, clothing factor for the winter cloth was taken as 1 clo. It is assumed that the occupant is relaxing on a sofa and producing 1 met heat. Whereas air humidity was taken as 50 $\%$. PPD index was calculated using the PMV based method by using equation 15 .

$$
P P D=100-95 \times e^{-\left(0.03353 \times P M V^{4}+0.2179 \times P M V^{2}\right)}
$$

The calculated PMV and PPD values should be in a range of $-0.5<$ PMV $<+0.5$ and PPD $<10 \%$, respectively [34]. Table 5 shows the comfort relating PMV scale.

Table-V: PMV Comfort scale

\begin{tabular}{ll}
\hline-3 & Cold \\
-2 & Cool \\
-1 & Slightly cool \\
0 & Neutral \\
1 & Slightly warm \\
2 & Warm \\
3 & Hot \\
\hline
\end{tabular}

Two parameters can be used for an alternative way of expressing the indoor thermal comfort, namely the comfort temperature $\left(T_{\text {comfort }}\right)$ and the operative temperature ( $\mathrm{T}_{\text {operative }}$ [24]. From equation 16 and 17 we can observe that the operative temperature evaluates the comfort temperature by considering air temperature, radiation temperature, and air velocity. While the operative temperature considers air temperature and radiation temperature only. Hence the comfort temperature preferred over the operative temperature throughout the study. The values of comfort, operative and radiation temperature can be calculated by the following equations,

$$
\begin{aligned}
& T_{\text {Operative }}=\frac{T_{\text {Radiation }}+T_{\text {Air }}}{2} \\
& T_{\text {Comfort }}=\frac{T_{\text {Radiation }}+T_{\text {Air }} \sqrt{\left(10 . U_{\text {Air }}\right)}}{1+\sqrt{\left(10 . U_{\text {Air }}\right)}}
\end{aligned}
$$




$$
T_{\text {Radiation }}^{4}=\frac{1}{4 . \sigma} \int_{0}^{4 \pi} I d \Omega
$$

\section{VALIDATION OF THE MODEL} environment using the Ansys Fluent software the RANS computations have been carried out for default inlet angle $\left(0^{\circ}\right)$ setting (Normal to $\mathrm{YZ}$ plane). Validation of a $3-\mathrm{D}$ empty modeled room has been done by comparing the present thermal comfort predictions with the earlier performed experimental [7] and numerical study [24, 32, and 33].

Fig. 3 and Fig. 4 shows the comparison of numerically anticipated comfort temperature with experimental and numerical results respectively. The acceptable agreement between predicted and published results was attained. A slight variation in trends can be seen for the experimental validation for the fluid domain $(y>1.5 \mathrm{~m})$ and in case of numerical validation in the center of the fluid domain $(1 \mathrm{~m}<\mathrm{y}<2 \mathrm{~m})$ for the line $\mathrm{l}_{1}$. The deviation in operative temperature trends is about $\pm 0.5^{\circ} \mathrm{C}$. Apart from this small variation, all the trends show the same pattern of the comfort temperature profile. This variation in trends is arising due to the presence of high turbulence and buoyancy effect near the inlet vent. Cold air stream near the inlet contributes to negative buoyant effect while the warm air rising from the radiator contributes to a positive buoyant effect, which creates high turbulence in that region. For additional validation of the model, the further volume flow rate has been calculated and found to be constant at $7.3 \mathrm{l} / \mathrm{s}$.

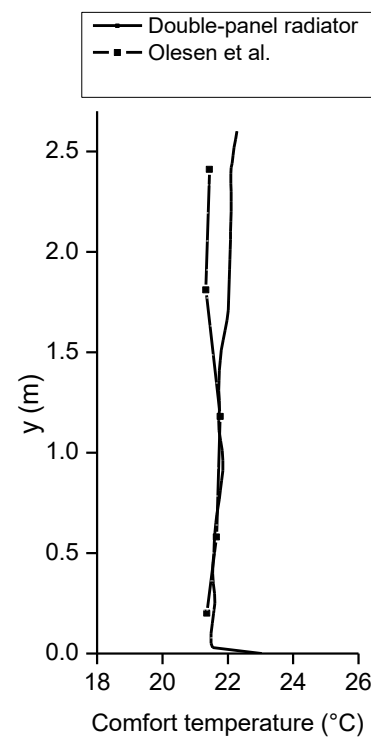

(a) $X=1 m$

Fig.3 Comparison of comfort temperature trends at $\mathrm{X}=1 \mathrm{~m}$ for unoccupied room model with previously published experimental results [7].

To analyze the indoor environment quality it is recommended to analyze various factors like total and radiation temperature along with air velocity, humidity, metabolic rate, clothing factors which affect the thermal comfort of the occupant. Hence to consider the overall effect of all the factors, PPD values based on PMV criteria were calculated using Equations (10, 14, and 15). The found
To study the predicted thermal comfort for the indoor

outcomes were compared with presented numerical estimates from alternative accessible numerical code Flovent at four different locations $l_{1}, l_{2}, l_{3}$ and $l_{4}$ (Fig.5) [24].

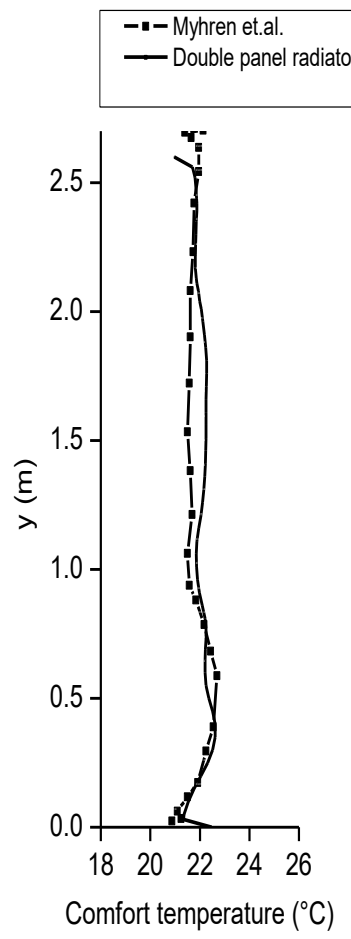

(a) $X=0.6 \mathrm{~m}$

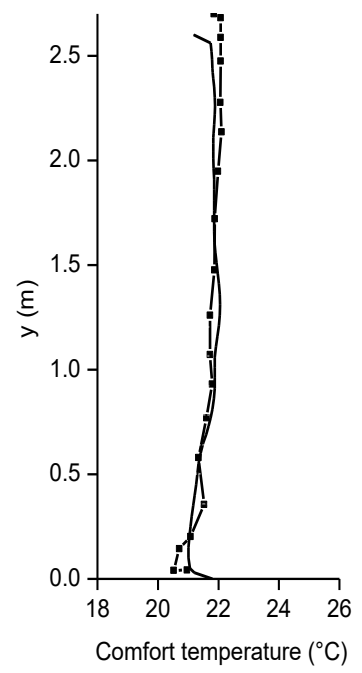

(b) $\mathrm{X}=1.2 \mathrm{~m}$

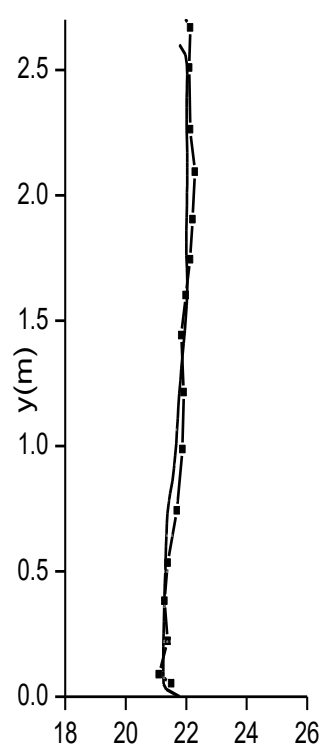

Comfort temperature $\left({ }^{\circ} \mathrm{C}\right)$

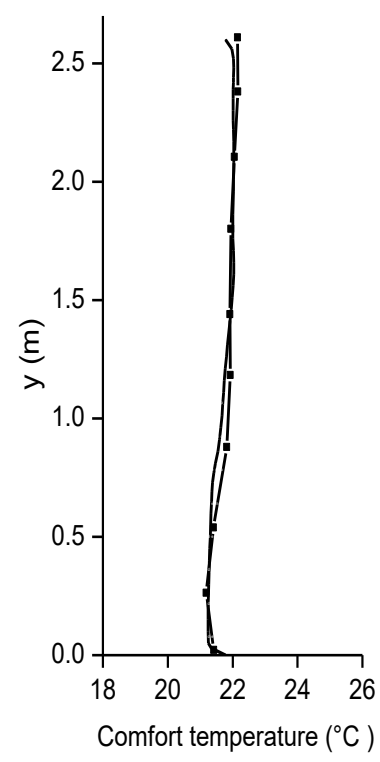

(c) $X=3.0 \mathrm{~m}$

(d) $X=4.2 m$

Fig.4 A comparison of the room temperature profile of this study and available results, at the four locations [24] (Z=0). (a) $I_{1}$, (b) $I_{2}$, (c) $I_{3}$, (d) $I_{4}$. 


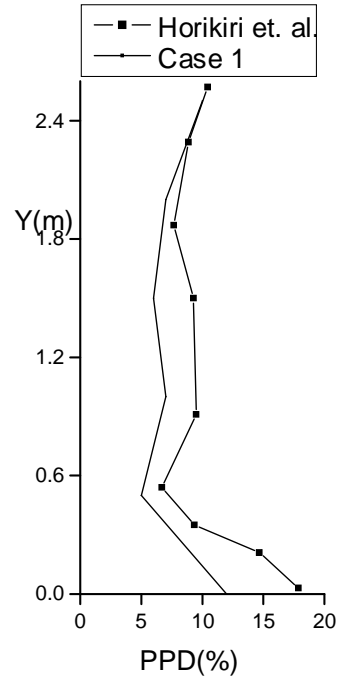

(a) $\mathrm{X}=\mathbf{0 . 6 \mathrm { m }}$

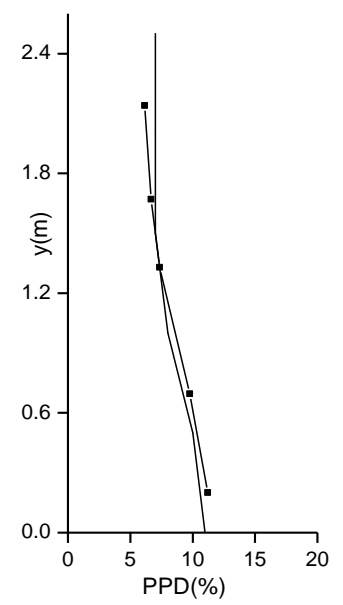

(c) $\mathrm{X}=3.0 \mathrm{~m}$

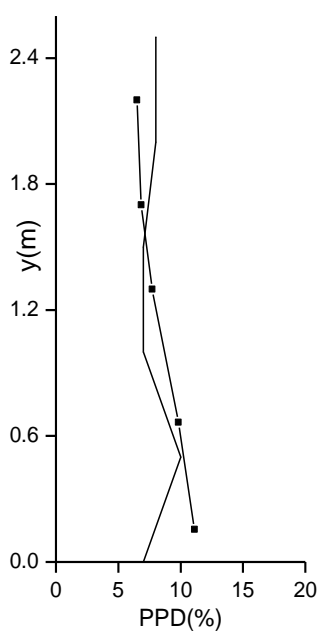

(b) $\mathrm{X}=1.2 \mathrm{~m}$

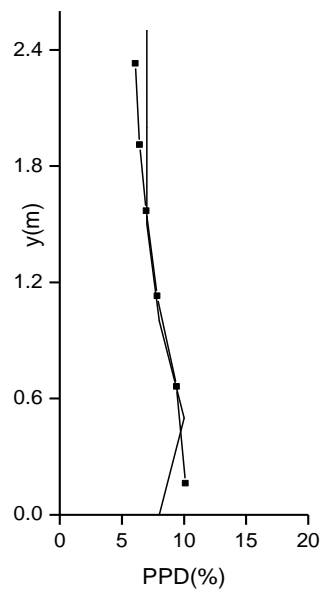

(d) $X=4.2 \mathrm{~m}$

Fig.5 Comparison of calculated PPD values based on PMV criteria at four locations with available numerical data $[24]$ (a) $l_{1}$, (b) $I_{2}$, (c) $l_{3}$, (d) $l_{4}$.

\section{RESULT AND DISCUSSION}

After obtaining a satisfactory result after the validation of the 3-D unoccupied room, CFD simulations for different cases were performed as mentioned in Table 3. The results of all case studies are plotted and compared as graphs. Also, the PPD and PMV indices were plotted for all the cases to compare the comfort level in the occupied zone.

\section{A. Effect of inlet angle on room air temperature}

For all the five cases, simulations were executed and comfort temperature calculated using equation 17. All the calculated results related to the comfort temperature were plotted and compared on the XY plot as shown in fig.6. From Fig.6 it is clearly seen that the effect of a change in direction of the cold airflow at the inlet is least on the indoor thermal conditions.
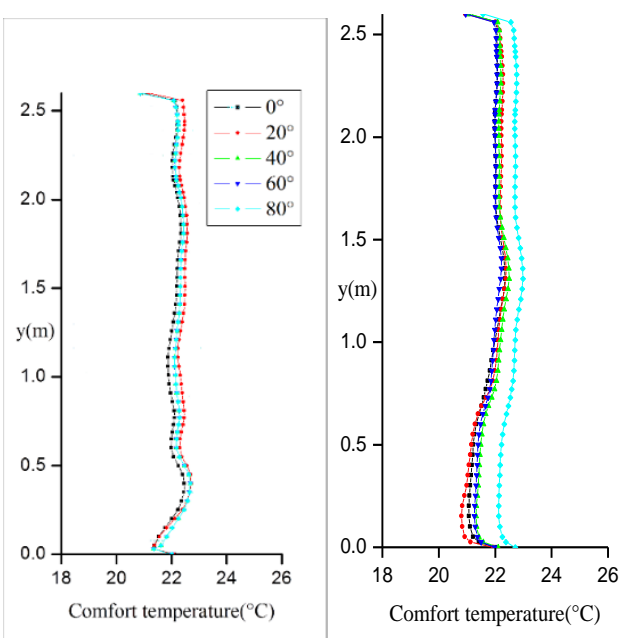

(a) $\mathrm{X}=0.6 \mathrm{~m}$

(b) $\mathrm{X}=1.2 \mathrm{~m}$

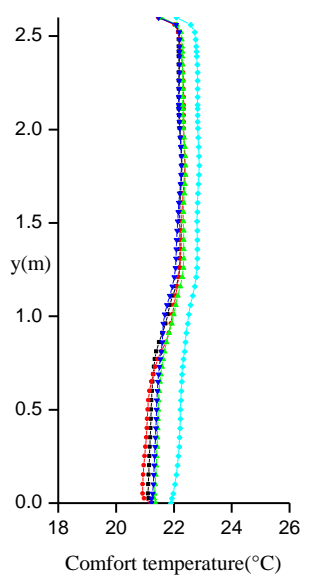

(c) $\mathrm{X}=3.0 \mathrm{~m}$

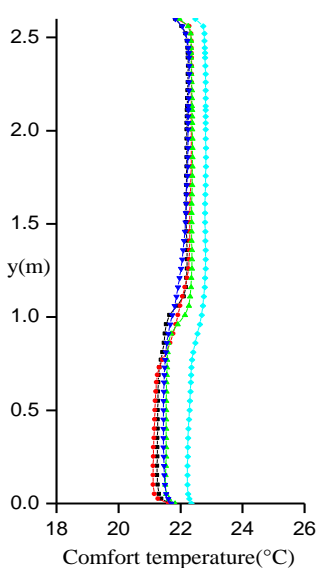

(d) $X=4.2 \mathrm{~m}$

Fig.6 Comfort temperature on midplane $(\mathrm{Z}=0)$ in the room throughout the height with various inlet vent angles at 4 monitoring lines (a) $l_{1}$, (b) $l_{2}$, (c) $l_{3}$, (d) $l_{4}$.

Fig.6 (a) shows a very small variation in comfort temperature trends for all cases since the domain close the inlet vent and radiator is of high turbulence and intermixing of cold and hot air streams takes place in this region. While for case 5, Fig.6 (b, c, and d) shows a large deviation in comfort temperature trends can be observed but the pattern of trends is the same. This variation in trend is arising due to the changed inlet angle. For case 5, the inlet angle changed to $80^{\circ}$, hence the inlet cold air stream strikes right on the radiator surface. For this case, the mixing fluid domain area of the cold and hot air stream is very small $(\mathrm{X}<1 \mathrm{~m})$ and immediate heating of cold air takes place. Hence the thermal effect of cold air stream on the occupied zone is found least in this case. However, in cases 1, 2, 3 and 4, the mixing of cold and hot air takes place in the large fluid domain and hence the thermal comfort temperature in the occupied zone is low as compared to case 5. From fig.6 it is clear that the direct impingement of fresh cold air stream on the radiator surface increases the average indoor comfort temperature by at least $1^{\circ} \mathrm{C}$. Fig. 7 shows the temperature distribution in the room on the midplane passing through the origin of the room $(\mathrm{Z}=0)$. 


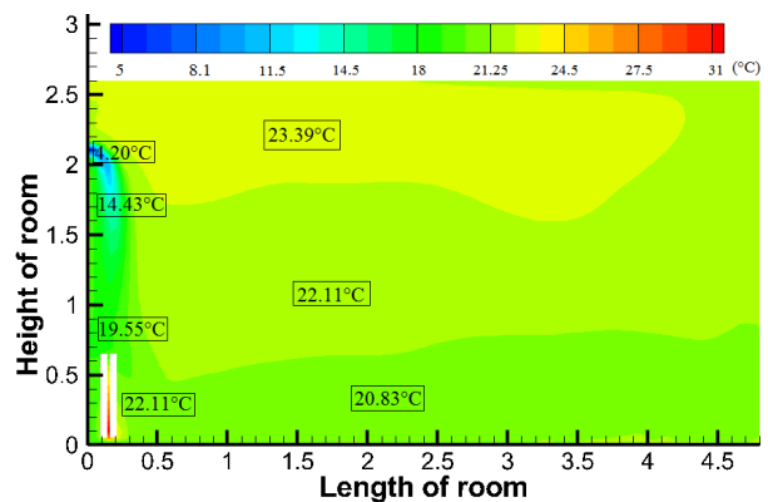

(a)

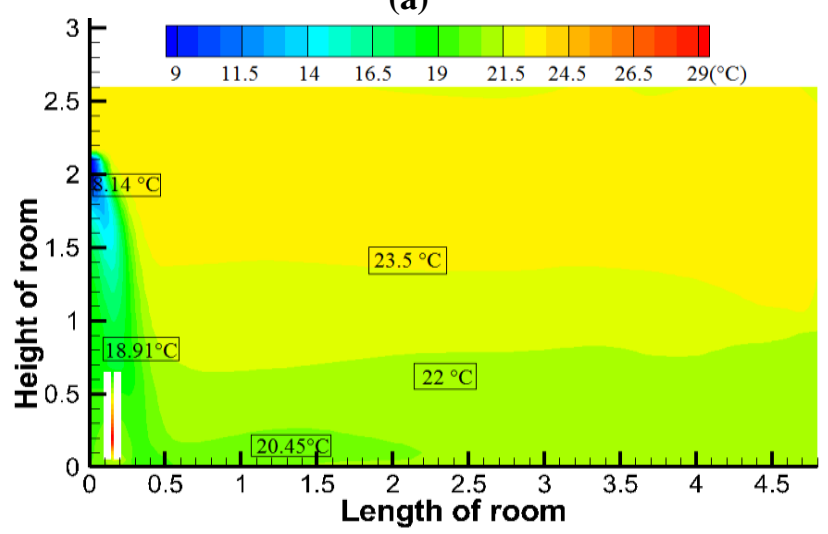

(b)

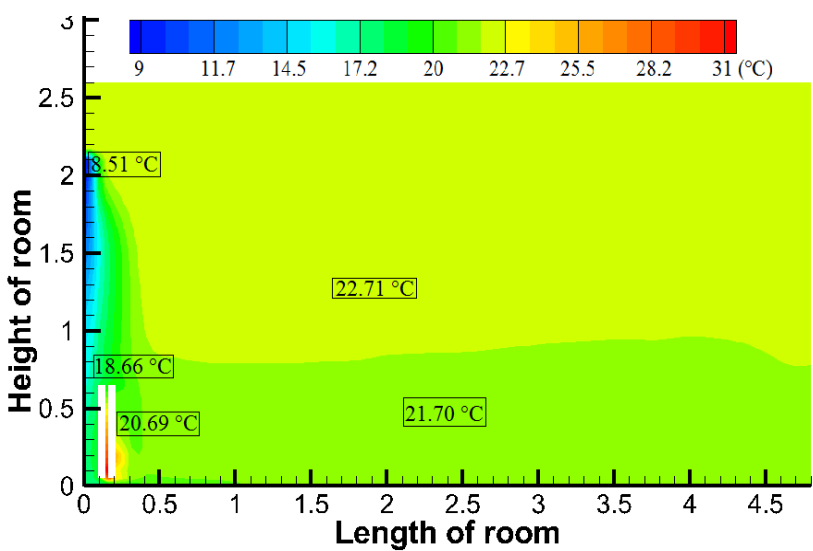

(c)

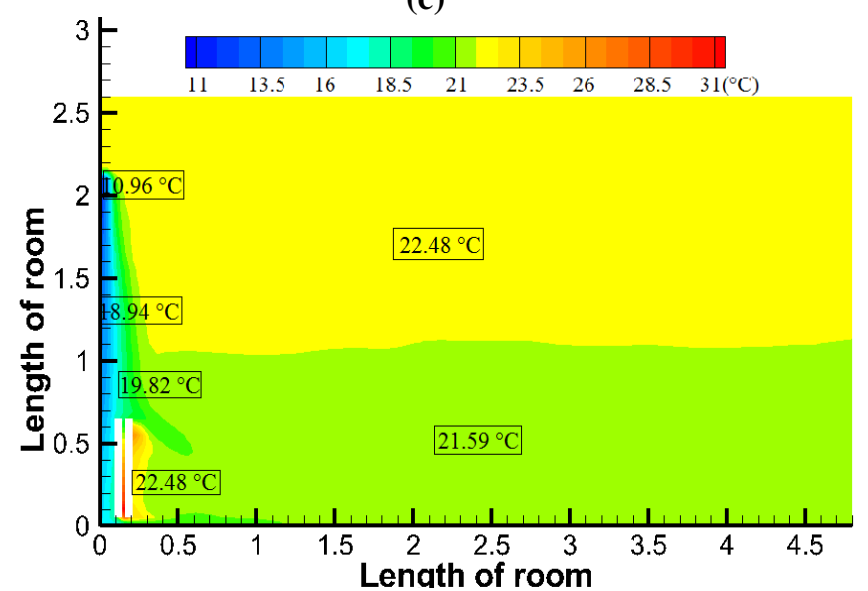

(d)

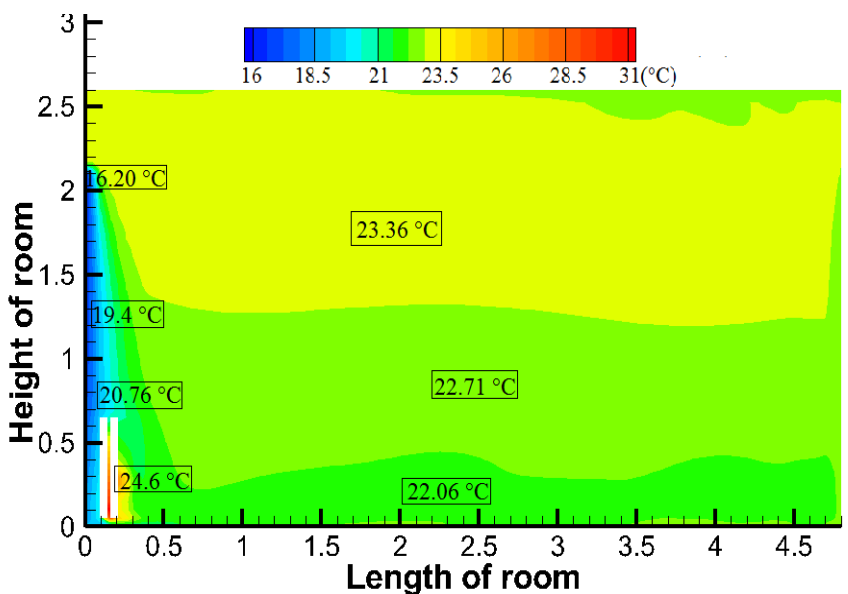

(e)

Fig.7 Total temperature contours at midplane $(Z=0)$ in room with various inlet vent angle in degrees (a) $0^{\circ}$, (b) $20^{\circ}$, (c) $40^{\circ}$, (d) $60^{\circ}$, (e) $80^{\circ}$.

The temperature contours show temperature distribution and the magnitude of temperature change at different locations. From fig. 7 it is observed that the cold and hot air stream mixing area decreases with the increase in inlet vent angle. While the Fig.7 (e) shows the higher average indoor temperature as compare to all other cases. Hence for better indoor thermal conditions in the occupied zone, it is recommended that the inlet cold air stream should maintain direct contact with the hot radiator surface.

\section{B. Effect of inlet angle on room airflow}

As mentioned in section 2.3 the volume flow rate of fresh air at inlet maintained constant at $7.3 \mathrm{l} / \mathrm{s}$. It is observed that when the inlet angle was changed the inlet vent projected area was decreasing simultaneously. Since the density of inlet air is constant, the volume flow rate directly proportional to the mass flow rate. From the conservation of mass principle, it is concluded that the decrease in inlet projected area results in a rise in inlet air velocity. Fig.8 shows the velocity vectors on the midplane passing through the room. It is clearly seen from the figure that, the velocity magnitude in the region near the radiator and inlet also increases as the inlet angle increases. Recirculation and swirling movement of air can be observed in the fluid domain. In the occupied zone, a large variation in Xdirectional velocity (u) was observed (Fig.8) as compared to $\mathrm{y}$ - directional velocity. Since the y velocity component influenced by buoyancy force, variation can be observed only near the inlet and radiator region.

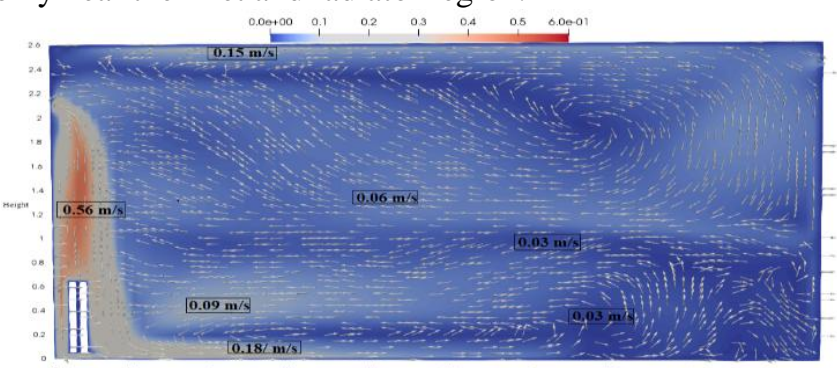

(a) 


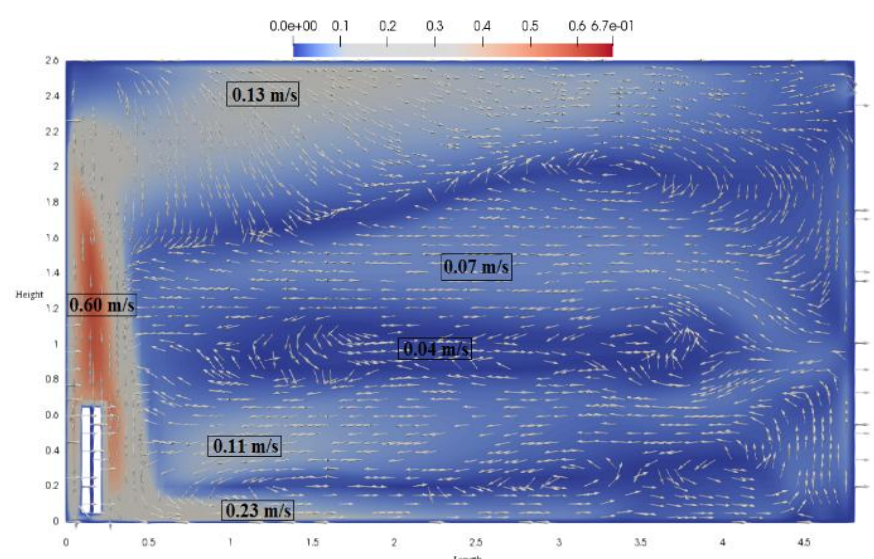

(b)

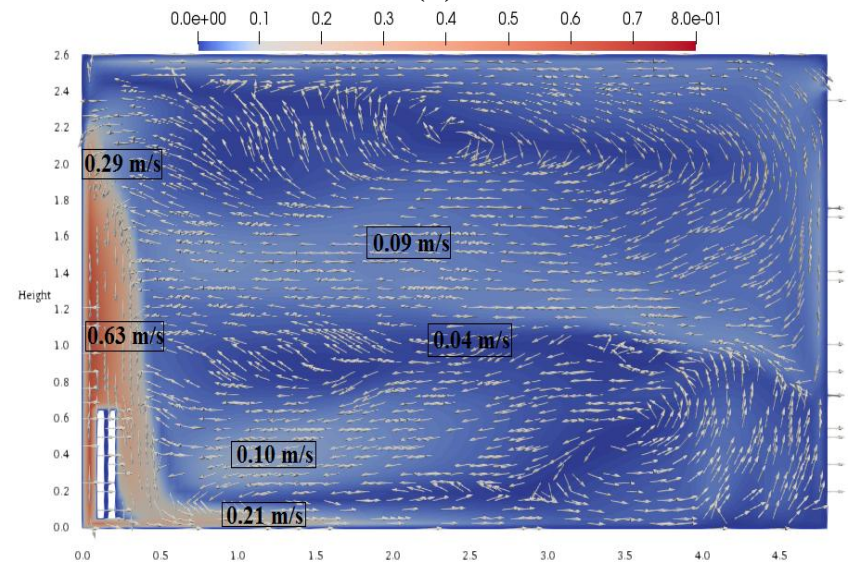

(c)

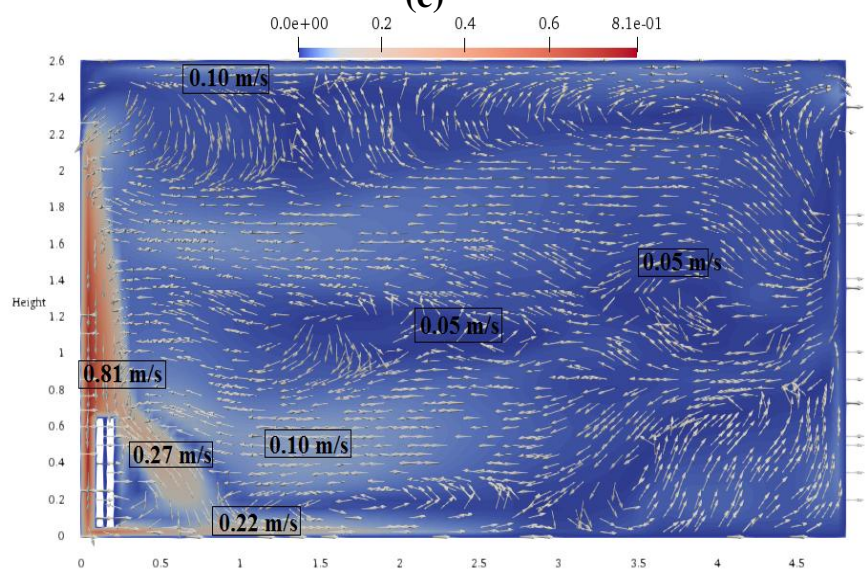

(d)

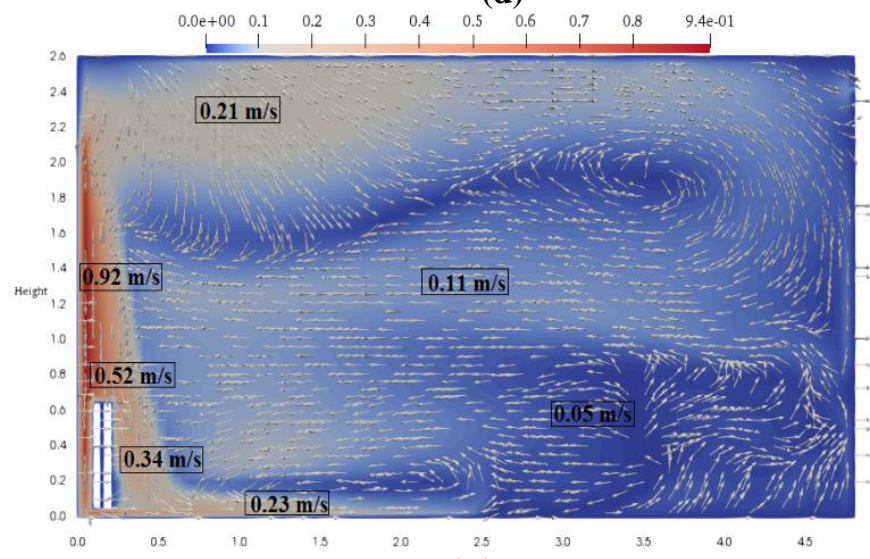

(e)

Fig.8 Velocity magnitude and direction at mid plane $(\mathrm{Z}=\mathbf{0})$ in a room for five cases (a) $0^{\circ}$, (b) $20^{\circ}$, (c) $40^{\circ}$, (d) $60^{\circ},(\mathrm{e}) 80^{\circ}$.
From fig.8 it is observed that the air movement in case of (a) and (e) was less as compared to other cases and may not cause discomfort to an occupant. As discussed earlier, the draught problem may arise due to high air movement (> $0.1 \mathrm{~m} / \mathrm{s}$ ) and low air temperature. Hence to get more exposure to air movement, Velocity magnitude, iso-surface of $>0.1 \mathrm{~m} / \mathrm{s}$ are plotted for the x-velocity (u) range of -0.7 $\mathrm{m} / \mathrm{s}$ to $0.7 \mathrm{~m} / \mathrm{s}$ for all the five cases.

Fig.9 shows the regions with velocity $(\mathrm{u})>0.1 \mathrm{~m} / \mathrm{s}$ which are located mainly in the domain near the floor and ceiling. Walls act as an obstacle to the airflow and cause the shear flow by high-velocity gradient at the walls and results into clockwise and anti-clockwise recirculation's in the top and bottom fluid domain respectively. Also, the positive and negative buoyant force also contributes to the velocity rise in ceiling and floor regions respectively.

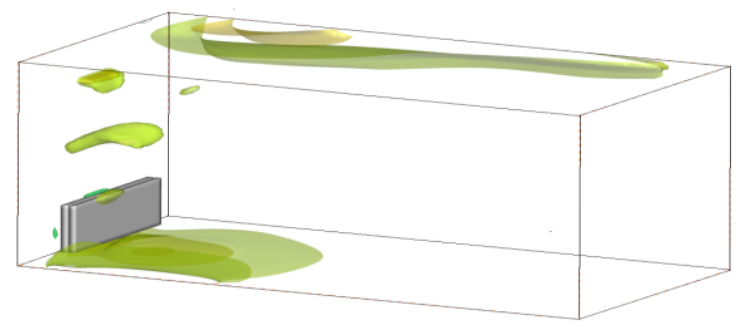

(a)

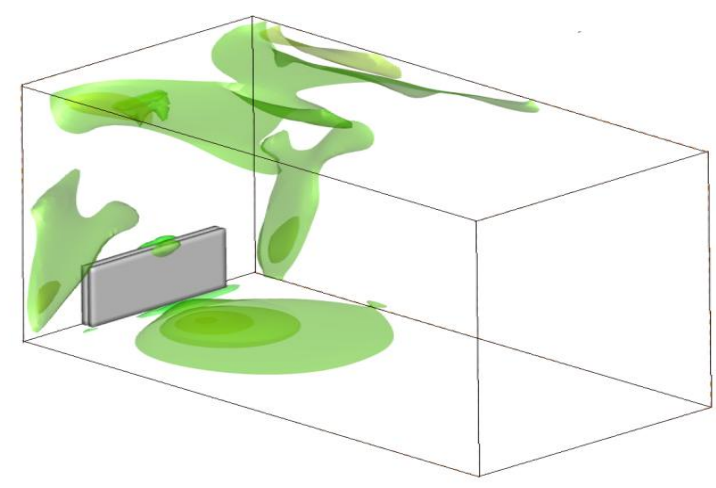

(b)

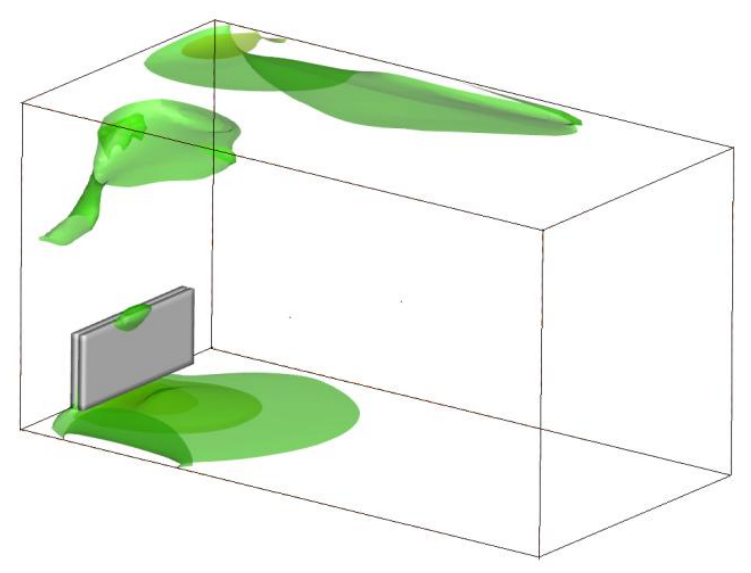

(c) 


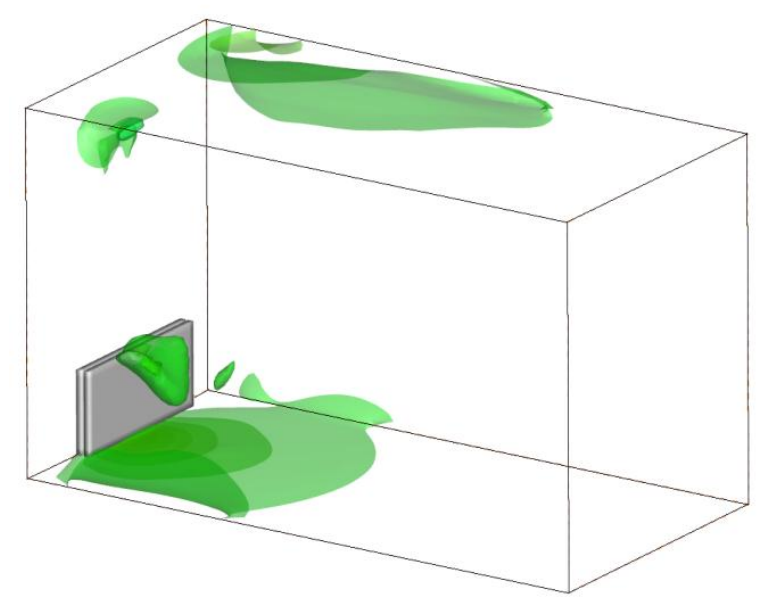

(d)

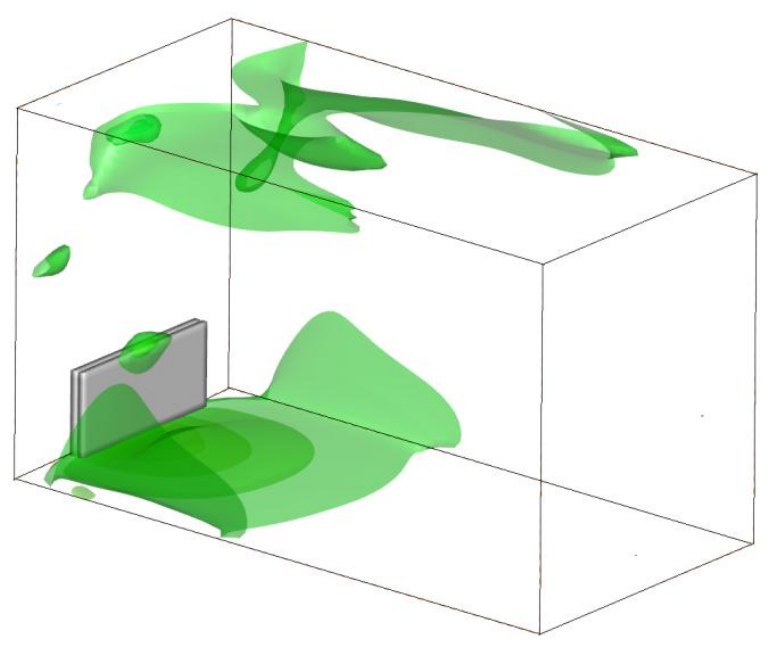

(e)

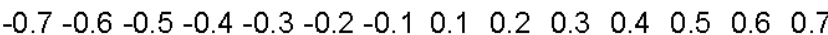

Fig.9. Iso-surface of $u>0.1 \mathrm{~m} / \mathrm{s}$ colored by $x$-velocity (u) contours for five cases with different inlet vent angle in degrees (a) $0^{\circ}$, (b) $20^{\circ}$, (c) $40^{\circ}$, (d) $60^{\circ}$, (e) $80^{\circ}$.

From all the above analysis, it was difficult to pick the precise model with more energy-saving and better thermal comfort conditions in the occupied zone. All the models having their own pros and cons related to temperature and airflow. Hence it is necessary to compute the PPD and PMV index for all the models. PPD index for all five cases was calculated at six different points in the y-direction $(0 \mathrm{~m}$, $0.5 \mathrm{~m}, 1 \mathrm{~m}, 1.5 \mathrm{~m}, 2 \mathrm{~m}$, and $2.5 \mathrm{~m}$ ) from floor level on each monitoring line $\left(l_{1}, l_{2}, l_{3}\right.$, and $\left.l_{4}\right)$.

From fig.10, it is clearly seen that the model with an $80^{\circ}$ inlet angle set shows the lowest PPD index at all the monitoring locations. The above PPD index was plotted for particular points in the fluid domain. For better understanding the average (overall) PPD and PMV index for occupied zone were plotted, average values of all the required properties (only in comfort zone) were taken for the calculation.

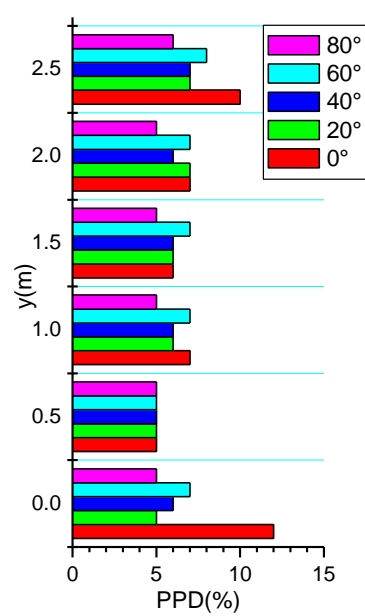

(a) $\mathrm{X}=\mathbf{0 . 6 \mathrm { m }}$

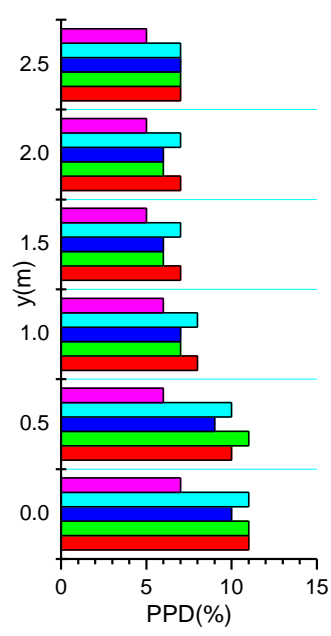

(c) $\mathrm{X}=3.0 \mathrm{~m}$

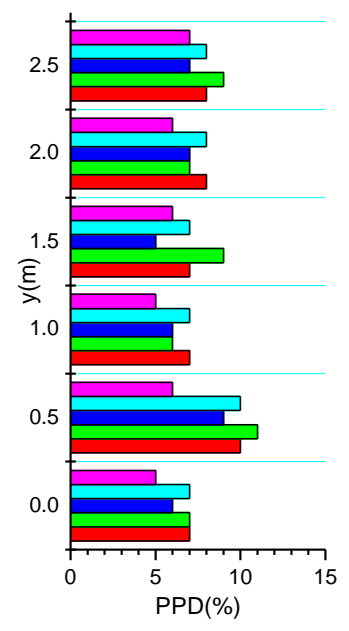

(b) $\mathrm{X}=1.2 \mathrm{~m}$

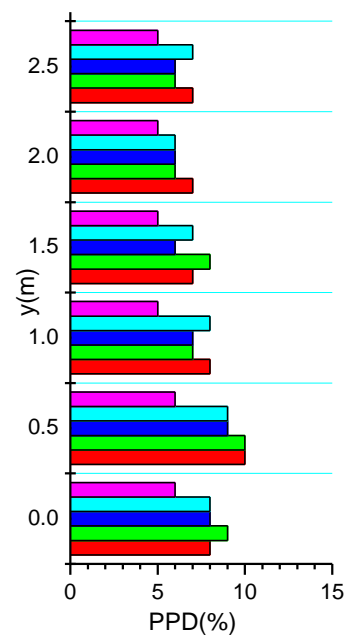

(d) $X=4.2 \mathrm{~m}$

Fig.10 PPD values in relation to PMV, at six upright points in y direction on four monitoring lines $(\mathrm{Z}=0)(\mathrm{a}) \boldsymbol{l}_{1}$, (b) $I_{2}$, (c) $I_{3}$, (d) $l_{4}$.

Fig.11 illustrates the average PPD index for all five cases. As described in section 2.5, observed values for PPD $<10 \%$ and PMV ranges between -0.5 to +0.5 (table 5 ). As per requirement $\mathrm{PPD}<10 \%$ acceptable, hence all the models are having desired comfort conditions. It is clearly seen

from Fig.11, the lowest PPD $(<5 \%)$ and PMV $(-0.16)$ index are shown for case $5\left(80^{\circ}\right.$ inlet angle) hence case 5 boundary conditions gives the best possible indoor comfort conditions.

From the above observations, it can be concluded that to maintain a comfortable indoor environment, the inlet cold air flow must be directed straight on the heating surface with high velocity. With the immediate contact of cold air and heating surface (radiator) the instant space heating of air takes place. Unwanted mixing of the cold air stream with air in the occupied zone can be avoided and helps to maintain the higher average room temperature. 


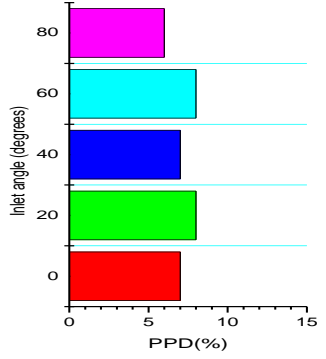

\section{Fig.11 Average PPD index plot for all the five case studies.}

\section{CONCLUSION}

In this study, CFD program was used to analyze the indoor environment quality of 3-D modeled empty room for different direction (angles) of cold airflow at the inlet.

- Alteration in the inlet air-jet angle affects the indoor environment quality. As the inlet jet angle increases the fresh air established good contact with radiator and overall air temperature increases.

- As the inlet vent angle increased from $0^{\circ}-80^{\circ}$ for constant volume flow rate, the inlet air velocity increases due to simultaneous reduction in the projected inlet vent area.

- As the inlet angle increases from $0^{\circ}-80^{\circ}$, the magnitude of $\mathrm{x}$-velocity (u) increases near the ceiling and floor area.

- As the inlet vent angle increases the airflow pattern for the indoor environment changes, more swirls and circulation are generated and can cause discomfort to the occupants.

- The direct impingement of cold inlet air on heat source immediately warms the inlet cold air and desirable PPD and PMV can be obtained in the indoor environment in a lesser amount of time.

Hence it is suggested to adjust the high-velocity inlet cold airflow direction in a way that the immediate contact of cold air and heating surface (radiator) must take place.

\section{REFERENCES}

1. Cao, X., Dai, X., \& Liu, J. (2016). Building energy-consumption status worldwide and the state-of-the-art technologies for zero-energy buildings during the past decade. Energy and Buildings, 128, 198213. https://doi.org/10.1016/j.enbuild.2016.06.089.

2. Yang, L., Yan, H., \& Lam, J. C. (2014). Thermal comfort and building energy consumption implications - A review. Applied energy, 115 ,

164-173. https://doi.org/10.1016/i.apenergy.2013.10.062.

3. Martínez-Molina, A., Tort-Ausina, I., Cho, S., \& Vivancos, J. L. (2016). Energy efficiency and thermal comfort in historic buildings: A review. Renewable and Sustainable Energy Reviews, 61, 70-85. https://doi.org/10.1016/j.rser.2016.03.018.

4. International energy agency key world energy (2007).

5. Ahmed, A. Q., \& Gao, S. (2015). Thermal comfort and energy saving evaluation of a combined system in an office room using displacement ventilation, International Journal of Mechanical, Aerospace, Industrial, Mechatronic and Manufacturing Engineering, 44(6), 1085-1090.

6. Yang, Q., Liu, M., Huang, C., Min, Y., \& Zhong, Y. (2015). A model for residential building energy consumption characteristics and energy demand: A case in Chongqing. Procedia Engineering, 121, 1772 1779. https://doi.org/10.1016/j.proeng.2015.09.154.

7. Olesen, B.W., Mortensen, E., Thorshauge, J., and Berg-Munch, B. (1980). Thermal comfort in a room heated by different method, ASHRAE Transactions, Los Angeles Meeting, vol. 86, Tech. Paper no. 2556.

8. Qasim, A., Gao, S., \& Khaleel, A. (2016). A numerical study on the effects of exhaust locations on energy consumption and therma environment in an office room served by displacement ventilation. Energy conversion and management, 117, 74-85. https://doi.org/10.1016/j.enconman.2016.03.004.

9. Ortiz, M. A., Kurvers, S. R., \& Bluyssen, P. M. (2017). A review of comfort, health, and energy use : Understanding daily energy use and wellbeing for the development of a new approach to study comfort. $\begin{array}{llll}\text { Energy } \quad \text { \& } \quad \text { Buildings, } & \text { 323-335. }\end{array}$ https://doi.org/10.1016/j.enbuild.2017.07.060.

10. Verma, T. N., \& Sinha, S. L. (2014). Contaminant control in the intensive care unit of a hospital. Applied Mechanics and Materials, 592-594(2231), 2486-2490 http://dx.doi.org/10.4028/www.scientific.net/AMM.592-594.2486.

11. Verma, T. N., Sahu, A. K., \& Sinha, S. L. (2018). Numerical Simulation of Air Pollution Control in Hospital. Air Pollution and Control. 185-206.ISBN 978-981-10-7185-0. https://doi.org/10.1007/978-981-10-7185-0_11.

12. Verma, T. N., Sahu, A. K., Sinha, S. L. (2017). Study of particle dispersion on one bed hospital using Computational Fluid Dynamics; Materials Today: Proceedings, Elsevier; Vol. 4, Issue 9, pp. 1007410079 https://doi.org/10.1016/j.matpr.2017.06.323

13. Verma, T. N., Sinha, S. L. (2018). Experimental and numerical investigation of contaminant control in Intensive Care Unit: A case study of Raipur, India; Journal of Thermal Engineering; Volume XX, No. X, pp. XXX-XXX (Accepted)

14. Sahu, A. K., Verma, T. N., Sinha, S. L. (2019).Numerical Simulation of Air Flow in Multiple beds Intensive Care Unit of Hospital; International Journal of Automotive and Mechanical Engineering (IJAME); Vol 16, Issue 2 pp. 6796-6807.

15. Verma, T. N., Sinha, S. L. (2013). Contaminant control in intensive care unit (ICU) using CFD modeling; International Journal of Mechanical and Industrial Engineering (IJMIE); ISSN No. 22316477, Vol-3, Iss-1,

16. Verma, T. N., Sinha, S. L. (2015). Trajectory of contaminated particle in intensive (ICU) of hospitals using numerical modeling, International Journal on Design \& Manufacturing Technologies (IJDMT); ISSN No. 0973-9106, Vol-9, Iss-1, p.p. 43-47.

17. Verma, T. N., Sahu, A. K., Sinha, S. L. (2017). Numerical simulation of air pollution control in hospital; Air Pollution and Control; Springer; $\quad$ p.p. 185-206; ISBN: 978-981-10-7184-3. (https://link.springer.com/chapter/10.1007/978-981-10-7185-0_11)

18. Sahu, A. K., Sinha, S. L., Verma, T. N., (2018). Numerical simulation of air flow to ventilate intensive care unit of hospital; Computer Application in Education and Research for Science and Technology; International Research Publication House (IRPH); p.p. 131-138; ISBN: 978-93-87388-21-5.

19. Roshan, G., Saleh, H., Queiroz, S., \& Attia, S. (2019). Urban Climate Estimate of outdoor thermal comfort zones for different climatic regions of Iran. Urban Climate, 27, 8-23. https://doi.org/10.1016/j.uclim.2018.10.005.

20. Salata F, Golasi I, Ciancio V, Rosso F, Dressed for the season: Clothing and outdoor thermal comfort in the Mediterranean population, Building, and Environment, 146, 50 63.https://doi.org/10.1016/j.buildenv.2018.09.041.

21. Nam, I., Yang, J., Lee, D., Park, E., \& Sohn, J. (2015). A study on the thermal comfort and clothing insulation characteristics of preschool children in Korea. Building and Environment, 92, 724-733. https://doi.org/10.1016/i.buildenv.2015.05.041.

22. Schiavon, S., \& Ho, K. (2013). Dynamic predictive clothing insulation models based on outdoor air and indoor operative temperatures. Building and Environment, 59, 250-260. https://doi.org/10.1016/j.buildenv.2012.08.024.

23. Carli, M. De, Olesen, B. W., Zarrella, A., \& Zecchin, R. (2007) People's clothing behavior according to external weather and indoor environment, Building and Environment, 42, 3965-3973. https://doi.org/10.1016/j.buildenv.2006.06.038.

24. Ganesh, G. A., Sinha, S. L., \& Verma, T. N. (2019). Numerical simulation for optimization of the indoor environment of an occupied office building using double-panel and ventilation radiator. Journal of Building Engineering, 29, 101139.https://doi.org/10.1016/j.jobe.2019.101139.

25. Kharseh, M., Altorkmany, L., Al-khawaj, M., \& Hassani, F. (2014) Warming impact on energy use of HVAC system in buildings of different thermal qualities and in different climates. Energy Conversion and Management, 81, 106-111. https://doi.org/10.1016/j.enconman.2014.02.001. 
26. Paliaga, G., Schoen, L. J., Alspach, P. F., Arens, E. A., Aynsley, R. M., Bean, R., Graef, P. T. (2014). Thermal Environmental Conditions for Human Occupancy, 8400. ISSN 1041-2336

27. S.A. Nada, H.M. El-Batsh, H.F. Elattar, and N.M. Ali, CFD investigation of airflow pattern, temperature distribution and thermal comfort of UFAD system for theater buildings applications, Journal of Building Engineering, 6, 274-300 http://dx.doi.org/10.1016/j.jobe.2016.04.008.

28. Fanger, P. O., Ipsen, B. M., Langkilde, G., Olessen, B. W., Christensen, N. K., \& Tanabe, S. (1985). Comfort limits for asymmetric thermal radiation. Energy and Buildings, 8(3), 225-236. https://doi.org/10.1016/0378-7788(85)90006-4

29. Lampret, Ž. Krese, G., Butala, V., \& Prek, M. (2018). Impact of airflow temperature fluctuations on the perception of draught, Energy \& Buildings 179, 112-120. https://doi.org/10.1016/j.enbuild.2018.09.014.

30. Tu, J., Yeoh, G.-H., \& Liu, C. (2018). Some Applications of CFD with Examples. Computational Fluid Dynamics, 291-367. https://doi.org/10.1016/B978-0-08-101127-0.00008-8.

31. Nielsen, P. V. (2015). Fifty years of CFD for room air distribution. Building and Environment, 91, 78-90. https://doi.org/10.1016/j.buildenv.2015.02.035.

32. Myhren, J. A., \& Holmberg, S. (2008). Flow patterns and thermal comfort in a room with a panel, floor and wall heating, 40, 524-536. https://doi.org/10.1016/j.enbuild.2007.04.011.

33. Myhren, J. A., \& Holmberg, S. (2009). Design considerations with ventilation-radiators: Comparisons to traditional two-panel radiators, Energy and Buildings 41, 92-100. https://doi.org/10.1016/j.enbuild.2008.07.014.

34. Srebric, J. and Chen, Q. (2002). "An example of verification, validation, and reporting of indoor environment CFD analyses," ASHRAE Transactions, 108(2), 185-194.

35. John Zhai, Zhiqiang \& Zhang, Zhao \& Zhang, Wei \& Yan Chen, Qingyan. (2007). Evaluation of Various Turbulence Models in Predicting Airflow and Turbulence in Enclosed Environments by CFD: Part 1-Summary of Prevalent Turbulence Models. HVAC \& Research,

13 ,

853-870. https://doi.org/10.1080/10789669.2007.10391459.

36. Launder, B. E., \& Spalding, D. B. (1974). The numerical computation of turbulent flows Computer Methods in Applied Mechanics and Engineering, 3, 269-289. https://doi.org/10.1016/00457825(74)90029-2.

37. Zhenhua, W., Zhihong, H., Lei, M., \& Shikui, D. (2015). Paralle algorithm and its convergence of spatial domain decomposition of discrete ordinates method for solving radiation heat transfer problem. Chinese Journal of Aeronautics, 28(1), 77-85. https://doi.org/10.1016/j.cja.2014.12.016.

38. Verma, T. N., \& Sinha, S. L. (2014). Numerical Simulation of Contaminant Control in the Intensive Care Unit, Journal of Medical Imaging and Health Informatics (5), 1-6. http://doi.org/10.1166/jmihi.2015.1500.

39. Al Assaad, D., Ghali, K., \& Ghaddar, N. (2018). The effectiveness of intermittent personalized ventilation assisting a chilled ceiling for enhanced thermal comfort and acceptable indoor air quality. Building and Environment, 144, 22.https://doi.org/10.1016/j.buildenv.2018.08.005

40. ANSYS Fluent Theory Guide. (2013), 15317, 724-746.

41. Cengel, Y.A. and Ghajar, A.J., (2017). Heat and Mass Transfer: Fundamentals and Applications, McGraw Hill Education.

42. Gaetani, I., Hoes, P., \& Hensen, J. L. M. (2016). Fit-for-purpose modeling strategy. Energy \& Buildings, 121, 188-204. https://doi.org/10.1016/j.enbuild.2016.03.038.

\section{AUTHORS PROFILE}

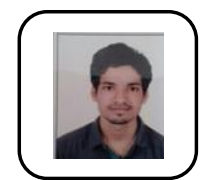

Ghogare Abhijeet Ganesh has completed a bachelor' degree (B.E.) in Mechanical Engineering from RTM Nagpur University. Completed Master's degree (Master of Technology) in Thermal and Fluids Engineering from NIT Manipur. Presently working as a Research Scholar (Ph.D.) at NIT Raipur in the department of Mechanical Engineering. The authors' work domain is in thermal comfort and IEQ.

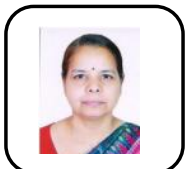

Dr. Shobha Lata Sinha working as a Professor in the department of mechanical engineering at NIT Raipur. The author is having a teaching experience of more than 15 years. The authors work domain is Alternative fuels, Biofluid mechanics, Computational Fluid Dynamics and published more than 90 research articles in renowned Journals.

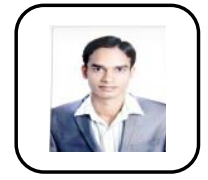

Dr. Tikendra Nath Verma working as an assistant professor in the department of mechanical engineering at NIT Manipur. His present areas of interest include Computational Fluid Dynamics, Heat \& Mass Transfer, Solar Energy, and Renewable Energy \& Alternative Fuels in Internal Combustion Engines. The author published more than 50 articles in the renowned journal.

\section{NOMENCLATURE}

No.

\begin{tabular}{|l|l|}
\hline$a$ & absorption coefficient \\
\hline$C_{l} C_{1 s} \quad C_{2 s}$ & $\begin{array}{l}\text { mode1 constants in the term of the turbulence } \\
\text { model }\end{array}$ \\
\hline$G_{k}$ & $\begin{array}{l}\text { generation of turbulence kinetic energy due to } \\
\text { the mean velocity gradient }\end{array}$ \\
\hline$G_{b}$ & $\begin{array}{l}\text { generation of turbulent kinetic energy due to } \\
\text { buoyancyl }\end{array}$ \\
\hline$k$ & turbulence kinetic energy \\
\hline$k_{\varepsilon \theta}$ & effective conductivity \\
\hline$S$ & heat sources \\
\hline$\vec{r}, \vec{s}$ & direction vector \\
\hline$\vec{r}, \vec{s}$ & scattering direction vector \\
\hline$m_{e}$ & metabolic equivalent \\
\hline$M_{1}$ & room mode1 1 using Double pane1 radiator \\
\hline $\begin{array}{l}M_{2} \\
\text { PPD }\end{array}$ & $\begin{array}{l}\text { room mode1 } 2 \text { using ventilation radiator } \\
\text { predicted percentage of discomfort } \\
\text { predicted mean vote }\end{array}$ \\
\hline
\end{tabular}

\begin{tabular}{|c|c|}
\hline$q$ & heat flux \\
\hline$S_{k}, S_{k}$ & source terms \\
\hline Ther & reference temperature \\
\hline$T_{\text {lead }}$ & temperature at head level \\
\hline Thast & temperature at foot level \\
\hline$V$ & velocity at inlet \\
\hline$u_{a j}$ & air velocity \\
\hline $\bar{v}$ & $\begin{array}{l}\text { a contribution of fluctuating dilatation in compressible } \\
\text { turbulence to the overall dissipation rate. } \\
\text { X-directional velocity }\end{array}$ \\
\hline \multicolumn{2}{|l|}{$\begin{array}{l}\text { Greek } \\
\text { letters }\end{array}$} \\
\hline$\varepsilon$ & dissipation of turbulent kinetic energy \\
\hline$P$ & density \\
\hline $\begin{array}{l}M \\
\theta\end{array}$ & $\begin{array}{l}\text { dynamic viscosity } \\
\text { inlet angle }\end{array}$ \\
\hline$\sigma$ & Stefan Boltzmann constant $(5.669 \times 10-8) \mathrm{W} / \mathrm{m}^{2}-\mathrm{K}^{4}$ \\
\hline $\begin{array}{l}g_{4} \\
\text { k从t }\end{array}$ & $\begin{array}{l}\text { scattering coefficient } \\
\text { turbulent viscosity }\end{array}$ \\
\hline$g_{4,} q_{\mathrm{g}}$ & turbulent Prandtl numbers for $\mathrm{k}$ and $\varepsilon$ respectively \\
\hline$\alpha$ & thermal diffusivity \\
\hline$\Phi$ & phase function \\
\hline$B$ & the coefficient of volume expansion \\
\hline$\Omega$ & solid angle \\
\hline$\therefore$ & scattering solid angle \\
\hline
\end{tabular}

